\title{
Eugenia, racismo científico e antirracismo no Brasil: debates sobre ciência, raça e imigração no movimento eugênico brasileiro (1920-1930)
}

\author{
Eugenics, Scientific Racism and Anti-racism \\ in Brazil: Debates about Science, Race and Immigration \\ in the Brazilian Eugenic Movement (1920-1930)
}

Vanderlei Sebastião de Souza*

\section{Resumo}

$\mathrm{O}$ artigo analisa os debates sobre eugenia, raça e imigração no Brasil nos anos 1920 e 1930, atentando para os antagonismos e as disputas entre os adeptos do racismo científico, que viam na questão racial o grande dilema nacional, e aqueles que negavam o determinismo racial, denominados aqui de "antirracistas". O autor destaca que a eugenia brasileira foi bastante polissêmica e mobilizou diferentes polêmicas científicas, raciais e políticas sobre miscigenação racial, seleção imigratória e branqueamento da população. $\mathrm{O}$ artigo explora especialmente os embates produzidos no Primeiro Congresso Brasileiro de Eugenia, realizado em 1929, e as ambivalências raciais promovidas no complexo contexto dos anos 1930, o que mobilizou distintos projetos e interpretações sobre eugenia, seleção racial e identidade nacional, in-

\section{Abstract}

The article analyzes the debates on eugenics, race, and immigration in Brazil in the 1920s and 1930s, paying attention to the antagonisms and disputes between supporters of scientific racism, who saw the racial issue as the great national dilemma, and those who denied racial determinism, here called "antiracists". The author highlights that Brazilian eugenics was quite polysemic and mobilized different scientific, racial, and political polemics about racial miscegenation, immigration selection, and population whitening. The article especially explores the clashes produced at the First Brazilian Congress of Eugenics, held in 1929, and the racial ambivalences promoted in the complex context of the 1930s, which mobilized different projects and interpretations on eugenics, racial selection, and national identi-

\footnotetext{
* Universidade Estadual do Centro-Oeste (UNICENTRO), Guarapuava, PR, Brasil.vanderleidesouza@ yahoo.com.br <https://orcid.org/0000-0003-4270-7445>
} 
clusive com impacto na Constituinte de 1933-1934.

Palavras-chave: Eugenia; Raça; Imigração; Racismo científico; Antirracismo. ty, including with impact on Constituent of 1933-1934.

Keywords: Eugenics; Race; Immigration; Scientific Racism; Anti-racism.

A eugenia emergiu no início do século XX como um movimento científico e social fortemente associado às teorias raciais e evolutivas em voga no período, sobretudo aquelas relacionadas ao racismo científico e ao darwinismo social. Em tempos de expansão do imperialismo europeu e das ideologias nacionalistas, as teorias eugênicas consolidavam a crença na existência de raças superiores e inferiores e na possibilidade de empregar a ciência e a técnica para eliminar as imperfeições humanas e apressar o processo de evolução biológica das futuras gerações. Nascida na Inglaterra no final do século XIX, a eugenia rapidamente se disseminou pelo mundo, formando, nas primeiras décadas do século XX, um movimento que contou com a audiência de estadistas, médicos, cientistas e intelectuais de diferentes nacionalidades e orientações políticas e ideológicas (Adams, 1990).

Como um campo que articulou ciência, política e raça, a eugenia promoveu ideias e medidas sobre seleção social e racial, gênero, sexualidade e formação das identidades nacionais, adequando os usos das teorias científicas às ideologias políticas e raciais correntes no período. Neste contexto, conforme lembra Nancy Stepan (2005, p. 9), a eugenia não apenas "encorajou a administração científica e racional da composição hereditária da espécie humana” como introduziu ideias potencialmente explosivas que incluíam a segregação racial, a esterilização compulsória e o racismo. Não é por acaso que, na memória social, a eugenia ficou especialmente associada aos horrores cometidos pelos nazistas contra judeus, doentes mentais, homossexuais e outras minorias étnicas e sociais. Contudo, violentas políticas eugênicas também foram implantadas em outros lugares do mundo, como Estados Unidos, Inglaterra, Alemanha, Noruega e Suécia, nações que institucionalizaram a eugenia e promoveram duras medidas de seleção social e racial. Muitos anos antes da ascensão do nazismo, eugenistas norte-americanos, por exemplo, já articulavam as ideologias de segregação racial e supremacia ariana com medidas radicais de esterilização eugênica e seleção imigratória (Kevles, 1985; Proctor, 1988; Adams, 1990; Stern, 2005).

Na América Latina, a eugenia emergiu no contexto da Primeira Guerra Mundial, estimulada pela necessidade de pensar a formação racial e as identi- 
dades nacionais. Movimentos eugênicos bem organizados surgiram sobretudo no Brasil, no México e na Argentina, que contaram com a criação de sociedades eugênicas, periódicos e eventos especializados. De maneira geral, os eugenistas latino-americanos se envolveram com legislações e medidas de bem-estar materno e infantil, combate às doenças infecciosas, saúde mental, educação sexual e matrimonial e controle reprodutivo, mas também com projetos relacionados às ideologias raciais particulares de cada país, muitas vezes em sintonia com o racismo científico que grassava na Europa e nos Estados Unidos (Stepan, 2005).

No caso do Brasil, embora a eugenia tenha sido introduzida a partir de estreita associação com a higiene e a medicina social, a historiografia tem destacado que as maiores polêmicas giraram em torno dos efeitos da miscigenação racial (Mota, 2003; Santos, 2003; Diwan, 2007; Habib, 2010; Carvalho, 2014; Wegner, 2017; Souza, 2019). Neste artigo, procuro justamente analisar como os eugenistas brasileiros lidaram com temáticas sobre mestiçagem, imigração e seleção racial, o que projetou uma série de polêmicas científicas, raciais e políticas que dividiu o movimento eugênico. Argumento que essa divisão marcou forte embate entre os adeptos do racismo científico, entre os quais se destacavam Renato Kehl, Azevedo Amaral e Xavier de Oliveira, e seus oponentes, nomeados aqui de "antirracistas", como Edgard Roquette-Pinto e Fróes da Fonseca, cujas teses antecipavam interpretações que, nos anos 1930, ganhariam proeminência com a obra de Gilberto Freyre sobre a valorização da mestiçagem brasileira, marcada pela publicação de Casa-Grande e Senzala em 1933.

Procuro demonstrar que os adeptos do racismo científico se baseavam em proposições que identificam a "questão racial" como responsável pela suposta inferioridade biológica e civilizacional do país. Essa variante do racismo, como explica Antonio Sérgio Guimarães (2005), surgiu na cena política e intelectual brasileira como doutrina científica a partir da geração de 1870 e se estendeu até pelo menos os anos 1930. Embora o racismo científico fosse bastante heterogêneo, existiam pontos em comuns que conectavam seus seguidores, como a crença na hierarquia racial, na superioridade europeia e na indissociável conexão entre caracteres biológicos e capacidades físicas, morais e intelectuais. O filósofo Tzvetan Todorov (2005) argumenta que o racismo científico foi um inexorável determinismo que nasceu na Europa entre os séculos XVIII e XIX sob o abrigo da ciência, como um esforço generalizado para ordenar e classificar as raças humanas, colocando os europeus no topo da pirâmide. Ainda de acordo com Todorov, o racismo científico foi bastante polissêmico e gerou um 
conjunto de preceitos que se impunha como racional, universal e moralmente superior, uma vez que se apresentava como legitimamente científico.

Por outro lado, defino como "antirracistas" os intelectuais que contestavam as bases desse racismo, atuando como cientistas e homens públicos que empregavam a ciência para refutar a afirmação de que os "males do Brasil" derivavam de fatores biológicos e raciais. Ao mesmo tempo, conforme argumento ao longo do texto, os intelectuais antirracistas defendiam que negros, indígenas e mestiços eram perfeitamente eugênicos e não apresentavam estigmas de degeneração ou inferioridade biológica. Embora os antirracistas aqui analisados incorporassem parte do ideário evolucionista do período, e muitas vezes expressassem preconceitos e visões ambíguas sobre a questão racial, partiam do princípio de que os problemas brasileiros não decorriam da formação racial, mas de questões sociais e políticas ligadas à educação, saúde pública e alimentação.

Destaco que os antagonismos entre os adeptos do racismo científico e os seus opositores foram travados especialmente no contexto de discussões sobre imigração, ocupação do território e formação da nacionalidade brasileira, temáticas que, desde o final do século XIX, mobilizavam a agenda política e intelectual do país. Vale lembrar que, pelo menos desde as discussões sobre a abolição da escravidão, ainda no Império, a seleção imigratória era vista como fundamental para se pensar a formação da nação e o futuro do país no chamado "concerto das nações" (Seyferth, 1996; Geraldo, 2007; Rebelo, 2010). Para compreender como essas discussões foram incorporadas nos anos 1920 e 1930 pelo movimento eugênico, analiso textos, discursos, livros e anais de eventos como o Primeiro Congresso Brasileiro de Eugenia, realizado em 1929. Ao mesmo tempo, investigo a atuação dos eugenistas na formulação de políticas de imigração promovidas no início dos anos 1930, quando uma ampla legislação imigratória foi discutida e aprovada.

\section{A EMERGÊNCIA DA EUGENIA E A QUESTÃO RACIAL NO PÓS-PRIMEIRA GUERRA}

A eugenia emergiu no Brasil logo após a Primeira Guerra Mundial, quando intelectuais e autoridades políticas voltavam suas atenções para os problemas da nacionalidade brasileira. Neste período, o país enfrentava uma grave crise política e social caracterizada pelo domínio das oligarquias rurais: exclusão social, analfabetismo, fome e enfermidades assolavam as populações urba- 
nas e rurais (Lima; Hochman, 1996). Além disso, o brasileiro era representado no exterior como racialmente inferior e incivilizado, marcado pela mestiçagem, pelo clima tropical e pela indolência física e moral, o que impactava na própria visão que as elites intelectuais mantinham do Brasil (Schwarcz, 1993). Neste contexto, a eugenia foi apropriada por médicos, intelectuais e autoridades políticas como ferramenta que permitia reformar a sociedade e regenerar a "raça nacional".

O movimento eugênico brasileiro ganhou proeminência a partir da fundação da Sociedade Eugênica de São Paulo, criada em 1918 sob a articulação de Renato Kehl, um jovem médico que se transformaria na grande liderança da eugenia brasileira (Diwan, 2007; Souza, 2019). Neste período, a adesão à eugenia mobilizou particularmente intelectuais, médicos e higienistas que integravam o chamado movimento sanitarista, entre eles Belisário Pena, Arthur Neiva, Afrânio Peixoto, Monteiro Lobato e Fernando de Azevedo. Em diálogo com o evolucionismo neolamarckista, que permitia pensar a herança dos caracteres adquiridos do meio, muitos eugenistas acreditavam que medidas de reformas sanitárias e educação higiênica garantiriam inclusive o aperfeiçoamento hereditário das futuras gerações, o que justificava afirmar que "sanear é eugenizar”, conforme afirmava Olegário de Moura (1919, p. 83), vice-presidente da Sociedade Eugênica de São Paulo. ${ }^{1}$

Apesar da centralidade do sanitarismo na eugenia brasileira, a questão racial ocupou espaço privilegiado, principalmente o debate sobre imigração, miscigenação racial e branqueamento. Não é por acaso que o grande dilema dos eugenistas consistia justamente em lidar com a mistura de raças, vista como responsável pelas mazelas do país. Uma alternativa encontrada pelas elites intelectuais brasileiras foi refutar a degenerescência dos mestiços e considerar a miscigenação como caminho para homogeneizar a população nacional. Essa percepção encontrava suporte na tese do branqueamento racial, intepretação bastante difundida no Brasil desde o século XIX. Em linhas gerais, a tese postulava que a ampla mestiçagem entre brancos, negros e indígenas conduziria ao branqueamento racial, uma vez que, na compreensão social-darwinista do período, predominariam as características do europeu, visto como "raça superior" (Schwarcz, 1993; Guimarães, 2005; Skidmore, 2012).

Em diálogo com a tradição sanitarista, alguns eugenistas afirmavam que a degeneração da população negra e mestiça brasileira derivava das péssimas condições de saúde e da miséria social em que viviam. Essa interpretação, contudo, era mesclada com análises oriundas do racismo científico, o que produzia diagnósticos ambivalentes. Em conferência na Sociedade Eugênica de São 
Paulo, o médico Rubião Meira afirmava que a "decadência da raça negra" estava relacionada ao abandono a que fora submetida após a abolição da escravidão, atirada a "vícios e paixões", alcoolismo, sífilis e tuberculose. Ao mesmo tempo, Meira afirmava que a degeneração dessa população, somada ao processo de mestiçagem com imigrantes europeus, estavam extinguindo os negros do território brasileiro. Em seu ponto de vista, essa mistura racial com europeus consolidava a formação de uma população eugênica, uma "nova alma" que colocaria o Brasil no contexto internacional como uma "nação forte e poderosa" (Meira, 1919, pp. 50-51).

Otimistas com essas perspectivas eugênicas, nos anos 1920 os eugenistas passaram a defender a seleção imigratória como medida essencial para o progresso biológico e social do Brasil. Campanhas em defesa da legislação imigratória tornaram-se frequentes em discursos, conferências e artigos publicados pelo movimento eugênico, chamando a atenção para a necessidade de impedir a entrada de "imigrantes indesejáveis". Eugenistas da Liga Brasileira de Higiene Mental (LBHM), instituição que deu amplo abrigo ao movimento eugênico, lembravam que a seleção imigratória era fundamental inclusive para evitar "problemas sociais" como a delinquência, a criminalidade, o alcoolismo e a loucura. Embora a Liga inicialmente tivesse assumido posições menos radicais sobre eugenia e seleção imigratória, fazendo a defesa de uma seleção individual ao invés de duros critérios raciais, a partir do final dos anos 1920 o racismo científico cada vez mais ocuparia espaço em sua agenda institucional (Reis, 1994; Munõz, 2018).

$\mathrm{Na}$ arena política, ainda nos anos 1920, conforme destaca Fernanda Rebelo (2010, p. 233), o governo brasileiro iria endurecer ainda mais o controle imigratório, ampliando a fiscalização nos principais portos do país, a exemplo do que vinha ocorrendo nos Estados Unidos e em outros países da América Latina. Ao mesmo tempo, o Congresso Nacional também discutia projetos de seleção imigratória, como a proposta apresentada pelo deputado Fidélis Reis, que propunha a restrição de "imigrantes indesejáveis", especialmente africanos e asiáticos. O projeto foi apresentado como substitutivo de outro projeto encaminhado anteriormente pelo deputado Cincinato Braga, que tinha como objetivo impedir a imigração de africanos, conforme fora cogitado em 1921 a propósito do envio de negros dos Estados Unidos para o Brasil (Ramos, 1994, p. 5). Nesse mesmo período, a Sociedade Nacional de Agricultura, entidade que articulava os interesses de parte das oligarquias rurais, também lançou inquérito para discutir quais seriam os imigrantes mais adequados para colonizar o território brasileiro. De acordo com Jair de Souza Ramos (1994), esse 
inquérito projetou amplo debate sobre os imigrantes mais desejados para suprirem as necessidades de mão de obra para a lavoura, ao mesmo tempo em que mirava questões ligadas à eugenia, civilização e assimilação racial.

A partir do final dos anos 1920, o debate sobre imigração ganharia ainda mais interesse político, mobilizando eugenistas e autoridade públicas que desejavam ampliar o controle sobre a entrada de estrangeiros no país. Neste contexto, discussões sobre miscigenação e seleção racial ganhariam novos contornos e dividiriam o movimento eugênico. Se até meados dos anos 1920 as teses do branqueamento e as agendas reformistas acomodavam visões racistas e antirracistas, no final dos anos 1920 o radicalismo eugênico criaria antagonismos que marcariam profundamente as discussões sobre a formação da identidade racial brasileira. Ao invés do otimismo em torno da miscigenação, o que passou a predominar foi uma visão pessimista fortemente temperada pelo racismo científico e pela crença na degenerescência dos mestiços.

\section{Mestiçagem e imigração no Primeiro Congresso Brasileiro de Eugenia}

O fortalecimento do movimento eugênico no final dos anos 1920 foi motivado pelo interesse que a eugenia despertava nos debates sobre raça, imigração e mestiçagem, mas também pela organização institucional que havia alcançado. Além da consolidação da LBHM como importante espaço de articulação dos eugenistas, em 1929 seria lançado o Boletim de Eugenia, periódico de propaganda eugênica que circularia até 1933. Criado e dirigido por Renato Kehl para promover a eugenia, o Boletim serviu como um instrumento oficial do movimento eugênico, sobretudo do grupo reunido em torno de seu editor, com destaque para nomes como Octavio Domingues e Toledo Pizza Junior, autoridades no campo da genética vegetal e animal que também atuaram no movimento eugênico, inclusive com passagem pela direção do Boletim de Eugenia (Habib, 2010).

Neste período, a eugenia se transformou em linguagem corrente, empregada tanto no campo da ciência, da educação e da literatura quanto no pensamento social e político ${ }^{2}$. Foi neste contexto que ocorreu no Rio de Janeiro, em 1929, o Primeiro Congresso Brasileiro de Eugenia, evento que contou com a audiência de intelectuais, jornalistas, autoridades públicas e médicos bastante renomados, entre eles Miguel Couto, Belisário Pena, Renato Kehl, Roquette-Pinto, Leonídio Ribeiro, André Dreyfus, Pacheco e Silva, Azevedo Amaral e 
Gustavo Riedel. Durante sete dias, os eugenistas apresentaram conferências, trabalhos e projetos envolvendo temáticas variadas, como seleção imigratória, esterilização eugênica, educação sexual, saúde mental, cuidado materno-infantil e higiene. Devido à centralidade que a questão imigratória alcançou naquele momento, as maiores polêmicas giraram em torno da miscigenação racial, especialmente pelas conferências de Azevedo Amaral, Renato Kehl, Xavier de Oliveira, Roquette-Pinto e Fróes da Fonseca.

A discussão proposta por Azevedo Amaral sobre "o problema eugênico da imigração" foi, sem dúvida, a que mais dividiu os participantes, uma vez que fazia amplas restrições à entrada de imigrantes no Brasil (Amaral, 1929). Médico de formação, jornalista e um aguerrido ideólogo do Estado autoritário, Amaral entendia que somente com a imposição de rígidas barreiras raciais seria possível uma seleção imigratória adequada, citando como exemplo o sucesso da recente política de imigração dos Estados Unidos (Amaral, 1929, p. 334). Adepto das teorias mendelianas, defendia que somente uma racional seleção biológica seria capaz de gerar "raças superiores", uma vez que o meio seria incapaz de corrigir os "defeitos das raças inferiores". Neste sentido, argumentava que deveriam ser aceitos no Brasil apenas correntes imigratórias da Europa, sendo "inadmissível a entrada de imigrantes da raça negra" e de outras regiões do mundo. Embora entendesse que havia no Brasil a predileção histórica pelos imigrantes da península ibérica e do mediterrâneo, defendia que, por razões de eugenia, o governo brasileiro deveria dar preferência aos imigrantes alemães e de países escandinavos, vistos como exemplos de "raças superiores" (Amaral, 1929, p. 336).

A conferência de Azevedo Amaral gerou amplo debate e divisões entre os participantes do evento. Apesar da concordância geral de que a seleção imigratória era imprescindível para a criação de uma nação eugênica, discordavam sobre quais aspectos deveriam ser levados em consideração, se aqueles de origem racial, como propunha Azevedo Amaral, ou se tão somente os fatores individuais ligados à saúde física e capacidade intelectual. A divisão claramente estava colocada entre os adeptos do racismo científico, aqueles que dividiam a humanidade entre raças superiores e inferiores e aqueles que refutavam as hierarquias raciais e a degenerescência das populações mestiças.

Entre os aliados de Azevedo Amaral encontravam-se nomes como Renato Kehl, Miguel Couto, Xavier de Oliveira, Oscar Fontenelle e Ernani Lopes, defensores de leis rigorosas de seleção eugênica. Para estes, a segregação racial era medida necessária para frear o "descontrolado" processo de miscigenação em curso no país. O psiquiatra e deputado federal Oscar Fontenelle, membro 
da LBHM, argumentava que os participantes do evento não poderiam deixar-se levar por "sentimentalismos", uma vez que o Brasil já teria sofrido demais com os "cruzamentos de raças diversas" (Actas do Congresso de Eugenia, 1929, p. 20). Assim como Amaral, Fontenelle lembrava o exemplo que os Estados Unidos davam ao mundo em matéria de legislação imigratória, referindo-se à aprovação de rígidas cotas de seleção imigratória pelo governo estadunidense, conhecida pela lei Johnson-Reed Act, aprovada em 1924.

Outro membro da LBHM, Xavier de Oliveira também apoiava as restrições de "imigrantes indesejáveis", como negros, árabes e asiáticos, cuja miscigenação com os brasileiros era vista como degenerativa. Por outro lado, defendia que o "cruzamento" de brasileiros com a raça branca, especialmente os latinos e anglo-saxões, gerava uma prole saudável, lembrando os resultados de seus estudos, apresentados no próprio Congresso de Eugenia, sobre os efeitos eugênicos da imigração europeia para a região nordeste do país. Oliveira inclusive apelava para que o Congresso de Eugenia aconselhasse o governo brasileiro a encaminhar imigrantes europeus para o Nordeste, ao mesmo tempo que tomasse medidas restritivas contra estrangeiros indesejáveis (Actas do Congresso de Eugenia, 1929, pp. 22-23). A proposta foi prontamente apoiada por outro representante do Nordeste no evento, o médico e deputado pernambucano Geraldo de Andrade, que afirmava ter realizado estudos antropológicos em mais de 10 mil pessoas e constatado que a "inferioridade dos mulatos é apavorante" (Actas do Congresso de Eugenia, 1929, p. 23).

Por outro lado, outros participantes do evento não apenas criticavam as propostas de restrição imigratória como contestavam as visões negativas sobre a população mestiça brasileira. Liderada pelo antropólogo Edgard Roquette-Pinto, a oposição às teses racistas era composta por médicos como Belisário Pena, Miguel Osório, Fernando Magalhães e Fernando da Silveira, pelo jurista Levi Carneiro e pelo antropólogo Fróes da Fonseca. Em primeiro lugar, se colocavam contrários à seleção imigratória baseada em critérios raciais, uma vez que defendiam a seleção a partir da análise das características individuais. No entendimento de Roquette-Pinto: “(...) o indivíduo passa na frente da raça quando se trata de aplicar os princípios da Eugenia à questão de imigração. Nesse particular, o essencial é que o imigrante seja homem individualmente são (física, moral e intelectualmente)" (Actas do Congresso de Eugenia, 1929, p. 16).

Ainda durante as discussões em torno da proposta de Azevedo Amaral, um segundo aspecto que mobilizou argumentos antirracistas foi a defesa da mestiçagem e a crítica às hierarquias raciais. Em sintonia com Roquette-Pinto, tanto Fernando Magalhães quanto Fernando da Silveira entendiam que a eu- 
genia não deveria excluir nenhum dos grupos humanos, uma vez que no "estágio atual dos caldeamentos raciais" não haveria "raças puras", tampouco superiores e inferiores. Nas palavras de Magalhães, "as restrições impostas às correntes imigrantes importam numa injustiça e num suicídio", já que "os pigmentos não excluem qualidades". E concluía: "há uma injustiça, por que todo o nosso passado se funda no mestiço, e há um suicídio porque todos somos mestiços e assim nos excluíamos" (Actas do Congresso de Eugenia, 1929, p. 20). Sentença ainda mais emblemática vinha da intervenção do médico e fisiologista Miguel Osório, que destacava que o Congresso de Eugenia deveria se basear tão somente pelas conclusões "verdadeiramente científicas", negando haver "hierarquia das raças". E numa provocação contra as teses racistas, questionava: "que diria um romano das raças gaulesas e germânicas, senão que eram inferiores?” (Actas do Congresso de Eugenia, 1929, pp. 20-21).

Durante o congresso, outras polêmicas giraram em torno do ideário racista de Renato Kehl. Embora tenha iniciado sua carreira nos anos 1910 como um aliado do movimento sanitarista, suas viagens à Alemanha como diretor da Bayer no Brasil, uma das maiores multinacionais alemãs, o colocaram em estreito contato com os movimentos eugênicos no norte da Europa, especialmente na Alemanha (Souza, 2019). Em sua conferência de abertura do congresso de eugenia, fazia longas referências aos eugenistas alemães e afirmava que "toda política" deveria "ser essencialmente uma política biológica", pautada na "higiene racial", conforme definiam os eugenistas germânicos (Kehl, 1929a, pp. 49-50). No início dos anos 1930, era comum inclusive se encontrarem referências elogiosas de Renato Kehl às políticas eugênicas implementadas pelo governo nazista (O Globo, 1934).

A maior polêmica envolvendo Renato Kehl e outros participantes do evento girava em torno do recente livro Lições de Eugenia, lançado e distribuído por Kehl justamente durante o Congresso. Além de caracterizar sua adesão à eugenia negativa, que consistia na defesa de medidas radicais de controle da reprodução humana, o livro apresentava uma visão bastante pessimista da miscigenação racial e dos mestiços brasileiros. Embora afirmasse que negros, indígenas e mestiços iriam desaparecer do Brasil "à custa de muito sabão de coco ariano", referindo-se ao aumento da imigração europeia e ao processo de branqueamento, entendia que os cruzamentos raciais geravam "tipos instáveis", "feios", "fracos" e "organicamente desequilibrados" (Kehl, 1929b, p. 191). Sob o ponto de vista eugênico, explicava que era contraindicado "qualquer união de raças distintas", uma vez que os mestiços se constituiriam como tipos híbridos inferiores. O "mulato", concluía ele, "representa o produto de fusão de 
energias hereditárias diversas, quase heterogêneas, fusão de cromossomos quase irreconciliáveis, e que só a benevolência da natureza permite se associarem" (Kehl, 1929b, p. 190).

A visão racista de Renato Kehl encontraria especial oposição em Roquette-Pinto e Fróes da Fonseca, antropólogos do Museu Nacional dedicados aos estudos sobre a formação racial brasileira. Os resultados dessas pesquisas seriam inclusive apresentados por Roquette-Pinto em conferência realizada no próprio congresso de eugenia. Desde o seu ingresso no Museu Nacional, em 1905, dedicava sua carreira ao estudo dos “tipos antropológicos do Brasil”, cujos resultados não apenas negavam a existência de hierarquias raciais como refutavam a tese da degenerescência dos mestiços (Souza, 2017). Conforme explicava aos participantes do congresso, a antropologia provava que "nenhum dos tipos da população brasiliana apresentava qualquer estigma de degeneração antropológica" (Roquette-Pinto, 1929, p. 146).

Embora Renato Kehl e Roquette-Pinto compartilhassem do evolucionismo mendeliano, a maneira com que empregavam a genética para compreender a miscigenação era bastante distinta. Enquanto Kehl via os cruzamentos raciais como mistura de características heterogêneas incompatíveis, Roquette-Pinto entendia que "a mestiçagem é combinação" de caracteres genéticos e antropológicos. A partir da análise da mistura racial entre a população brasileira, argumentava o antropólogo, ficava "provado mais uma vez que o cruzamento, longe de ser uma fusão ou caldeamento, seguiu aqui leis biológicas já conhecidas, e de nenhum modo - documentadamente - pode ser considerado fator disgênico" (Roquette-Pinto, 1929, p. 146).

Importante observar que Roquette-Pinto se opunha ao racismo científico utilizando-se das próprias ferramentas que a biologia evolutiva disponibilizava naquele momento. O uso que fazia desse evolucionismo permitia não apenas ver a mestiçagem como fator positivo, mas também assumir uma visão sociológica que apontava os males do Brasil como relacionados à falta de organização nacional, sobretudo aos problemas de saúde e educação. Neste sentido, se o antropólogo encontrava explicações biológicas num amplo diálogo com a genética e a antropologia física, seu olhar sociológico era tributário das tradições intelectuais brasileiras: em primeiro lugar, aos pensadores sociais como Euclides da Cunha, Manoel Bomfim e Alberto Torres, mas também ao próprio movimento sanitarista, que rejeitou o determinismo racial e teve um papel central na identificação da doença como o elemento distintivo da condição de ser brasileiro (Lima; Hochman, 1996, p. 23).

Posição muito semelhante era defendida por Fróes da Fonseca, antropó- 
logo treinado no próprio Museu Nacional e figura próxima a Roquette-Pinto. Em sua conferência, também refutava teses deterministas, afirmando que já era definitivo na antropologia que a mestiçagem não gerava inferioridade ou qualquer outro problema. Plenamente consciente dos equívocos do racismo científico, fazia duras críticas aos "pregoeiros do sangue ariano", eugenistas que produziam "teses doutrinárias" "distorcidas" e "ajeitadas" de acordo com seus preconceitos. Esse seria o caso, segundo Fróes da Fonseca, "do livro que acaba de ser distribuído por ocasião deste congresso, pelo Dr. Renato Kehl, sob o título 'Lições de Eugenia". Os conceitos e "erros por ele perpetrados", destacava ele, deveriam ser atribuídos à influência de "livros paracientíficos" como os de Madison Grant, obras de "larga repercussão nos meios pouco aptos para a leitura crítica” (Fonseca, 1929, p. 78).

Essa associação que Fonseca fazia entre Kehl e Madison Grant é emblemática e merece ser destacada. Como se sabe, Grant é considerado um dos grandes ideólogos da supremacia branca nos Estados Unidos, autor de The passing of the great race, livro saudado por ninguém menos que Adolf Hitler, e que serviu como inspiração ao arianismo nazista (Spiro, 2009, p. 357). Ao lado dos eugenistas, e também racistas, Charles Davenport e Lothrop Stoddard, nos anos 1920 Grant liderou ampla disputa pelo domínio da antropologia americana, rivalizando com o grupo de antropólogos formado em torno de Franz Boas, crítico ferrenho do racismo e do radicalismo eugênico norte-americanos (Spiro, pp. 297-310). Estrategicamente, Fróes da Fonseca associava Kehl a esse movimento "arianista", desqualificando seu opositor, ao mesmo tempo em que indicava a aproximação de sua antropologia com o antirracismo de Franz Boas. Em sua conferência no Congresso de Eugenia, afirmava que os trabalhos de Boas demonstravam "cientificamente" não haver raças superiores, e citava o conceito de cultura do antropólogo de Columbia para explicar que as diferenças entre os grupos humanos não diziam respeito às questões raciais, mas sim ao meio (Fonseca, 1929, p. 77).

\section{A EUgenia E AS AMbIVALÊNCIAS RACIAIS NOS ANOS 1930}

O debate sobre eugenia foi ainda mais emblemático no complexo contexto dos anos 1930, marcado pela crise do liberalismo e a ascensão de regimes autoritários e nacionalistas (Ferreira; Delgado, 2019). Neste contexto, o racismo e a eugenia foram colocados na ordem dia, empregados como políticas de Estado em diferentes lugares do mundo. O caso mais emblemático, como já mencionamos, foi sem dúvida o uso que a Alemanha nazista fez da eugenia em 
sua política de extermínio de minorias raciais. Contudo, não se pode esquecer que boa parte dos países ocidentais assistiram com naturalidade à escalada racista que incendiou a Europa, os Estados Unidos e a própria América Latina. Ao mesmo tempo, os anos 1930 também marcaram o fortalecimento do antirracismo e de inflexões sobre o conceito de raça, inclusive no campo da genética e da biologia evolutiva (Kevles, 1985).

No caso do Brasil, a década de 1930 representou uma série de ambivalências intelectuais e políticas, expressas nas diferentes ideologias que o governo Vargas procurou acomodar ainda antes da implantação do Estado Novo. Ao mesmo tempo em que estimulou políticas progressistas e assumiu a ideologia do Brasil mestiço, Vargas também aderiu às agendas reacionárias e racistas. Seu governo também ficaria marcado pela promoção do Estado nacional e pela criação de instituições que almejavam intervir na saúde pública, na educação e na assistência social (Schwartzman; Bomeny; Costa, 2000; Fonseca, 2007; Ferreira; Delgado, 2019). Para o movimento eugênico, Vargas representava a possibilidade de intervenção da eugenia tanto em assuntos de reforma social quanto em medidas de seleção racial, sobretudo de controle imigratório.

As disputas e os antagonismos vistos durante o Congresso de Eugenia ganharam contornos ainda mais emblemáticos nesse início dos anos 1930, introduzindo uma agenda de questões que orientaram os rumos do movimento eugênico. Não é por acaso que muitos participantes do evento continuaram exercendo protagonismo nas discussões sobre imigração, mestiçagem e seleção eugênica. Renato Kehl, por exemplo, se consolidaria como o principal articulador da eugenia brasileira, tendo inclusive fundado, em 1931, a Comissão Central Brasileira de Eugenia, órgão criado com o objetivo de assessorar o governo brasileiro em assuntos eugênicos. A comissão reuniria inclusive lideranças da LBHM, instituição que manteria sua influência no debate sobre eugenia, especialmente a partir de nomes como Ernani Lopes, Xavier de Oliveira, Pacheco e Silva, Cunha Lopes e Oscar Fontenelle (Reis, 1994; Muñoz, 2018).

Nos anos 1930, além de uma articulada campanha na imprensa, a defesa de uma eugenia mais dura ganharia abrigo nas páginas do Boletim de Eugenia e dos Archivos Brasileiros de Higiene Mental. Esse entusiasmo em torno do extremismo eugênico pode ser observado nos elogios às políticas de esterilização implantadas na Alemanha pelos nazistas. Em 1934, por exemplo, o periódico da LBHM saudava a recente implantação da lei de esterilização na Alemanha, publicando na íntegra o texto da lei aprovado pelo tribunal eugênico alemão (Wegner; Souza, 2013, pp. 274-275). A lei também seria amplamente noticiada na imprensa, como se pode observar no inquérito realizado pelo 
jornal O Globo junto aos eugenistas Renato Kehl, Pacheco e Silva, Oscar Fontenelle e Leonídio Ribeiro, que manifestaram opinião favorável à esterilização como medida de seleção racial, além de Roquette-Pinto e Leitão da Cunha, contrários à implantação da lei (O Globo, 1934).

Apesar da esterilização não ter sido aprovada no Brasil, a maneira como foi saudada ajuda a compreender como as ideias mais radicais tiveram adesão do movimento eugênico. Em alguns casos, o próprio conceito de "higiene racial" tornou-se comum no vocabulário do período, especialmente entre os membros da LBHM, o que reforçava a aproximação dos eugenistas brasileiros com a Alemanha nazista (Muñoz, 2018). Essa identidade em comum ficava expressa também na tradução de textos de eugenistas alemães no Brasil, ou mesmo na publicação de livros estreitamente sintonizados com as perspectivas arianista. Um exemplo emblemático nesse sentido foi o lançamento da obra Sexo e civilização - aparas eugênicas, publicada em 1933 por Renato Kehl. O livro não apenas aprofundava o interesse pela eugenia negativa como explicitava um ideário fortemente alinhado com o racismo científico. Assim como já aparecia em outros escritos seus, Kehl apontava que "o grande mal do Brasil é um mal de raça", cujo remédio só poderia ser encontrado numa racional política de seleção racial, que ele chamava de "política biológica" (Kehl, 1933, p. 204).

Como já era possível notar desde os embates no Congresso de Eugenia, nos anos 1930 o radicalismo eugênico encontraria amplo abrigo nas discussões sobre imigração. Aliás, em poucos lugares do mundo, com exceção feita aos Estados Unidos, a eugenia se identificou tanto com a questão imigratória quanto no Brasil. Durante o governo Vargas, a insistente preocupação em torno da identidade nacional projetou no debate sobre eugenia e imigração o caminho para a regeneração e o futuro do país. Não é por acaso que a legislação imigratória foi amplamente discutida durante a Assembleia Constituinte de 19331934, mobilizando intelectuais, eugenistas, parlamentares e o próprio governo Vargas. Conforme destaca Endrica Geraldo (2007, pp. 60-67), uma das prioridades de Vargas era justamente regulamentar a questão imigratória, vista como fundamental tanto para atrair trabalhadores saudáveis quanto para a ocupação do território nacional e a formação eugênica do país.

Durante as discussões da Constituinte, o movimento eugênico organizou uma ampla ofensiva em defesa da seleção imigratória, articulando seus canais oficiais, a imprensa e parte dos deputados que integravam a Assembleia, muitos deles médicos e intelectuais dispostos a atender as demandas eugênicas. Entre os parlamentares ligados ao movimento eugênico encontravam-se médicos como Arthur Neiva, Miguel Couto, Pacheco e Silva e Xavier de Oliveira, nomes 
que desde os anos 1920 faziam amplo lobby pelo controle imigratório. De maneira geral, esses parlamentares eram contrários à entrada de negros, árabes e asiáticos, uma vez que julgavam que a miscigenação com esses imigrantes seria prejudicial à construção nacional, sobretudo no que dizia respeito ao processo de branqueamento (República dos Estados Unidos do Brasil, 1935).

Conforme é possível perceber nos Anais da Assembleia, as discussões sobre seleção imigratória foram sustentadas por argumentos eugênicos, retomando inclusive teses defendidas durante o Congresso de Eugenia de 1929. Figuras como Renato Kehl, Roquette-Pinto, Azevedo Amaral e Oliveira Vianna, ou mesmo eugenistas estrangeiros eram citados nos discursos parlamentares. O deputado Miguel Couto, por exemplo, chegou a ler na plenária da Assembleia as conclusões do trabalho que Azevedo Amaral havia apresentado no Congresso de Eugenia, defendendo uma rigorosa seleção dos imigrantes (Couto, 1935, pp. 491-493). Nas discussões sobre miscigenação racial, arianistas como Madison Grant e Vacher de Lapouge, e aliados da higiene racial alemã, como John Alfred Mjoen, Fritz Lenz e Herman Lundborg, eram acionados para sustentar argumentos contrários à entrada de imigrantes não europeus. Xavier de Oliveira (1935, pp. 449-482) fazia longos discursos citando estes eugenistas para se opor aos estudos favoráveis à miscigenação racial, especialmente àqueles desenvolvidos por Roquette-Pinto, várias vezes mencionados entre os parlamentares como um crítico do radicalismo eugênico e racial.

Xavier de Oliveira era inclusive o deputado que mais mobilizava argumentos eugênicos para justificar a proibição de imigrantes indesejáveis. Em sua opinião, o problema imigratório fundamental estava relacionado à seleção eugênica, portanto, não seriam de ordem econômica ou política, como defendiam alguns. É por esse motivo que o deputado recorria às leis de imigração dos Estados Unidos, país que, segundo ele, melhor estabelecia critérios de seleção imigratória. Seguindo o exemplo norte-americano, o deputado cearense defendia que somente a imigração europeia deveria interessar ao Brasil, uma vez que o ingresso de raças não brancas ameaçaria o processo de branqueamento. Oliveira chegou a ler em plenária uma declaração de Renato Kehl enviada à Assembleia Constituinte, na qual chamava a atenção para o perigo que a mestiçagem com "raças heterogênicas" representava para o futuro do Brasil (Oliveira, 1935, p. 473).

Embora a Assembleia divergisse em diferentes pontos, havia a compreensão quase generalizada que uma legislação restritiva era necessária para garantir uma futura homogeneidade racial. De maneira geral, os parlamentares concordavam que a imigração europeia era a mais desejável, enquanto a entrada 
de imigrantes asiáticos, árabes, judeus e negros deveria ser vista com ampla preocupação. Neste sentido, viam a mestiçagem entre brasileiros e europeus como positiva, enquanto os cruzamentos com não branco eram apontados como uma questão "perturbadora e inassimilável". Como resultado final, a Assembleia aprovou uma legislação restritiva e racista que coroava as demandas do movimento eugênico e dos adeptos do racismo científico. Tendo como referência a legislação norte-americana de 1924, o Brasil também aderia a uma lei de cotas que favorecia amplamente a imigração europeia e restringia a entrada de outras nacionalidades (Seyferth, 1996; Geraldo, 2007).

Ao mesmo tempo em que a década de 1930 foi marcada pela escalada racista, também foi acompanhada pelo fortalecimento de críticas ao racismo e à própria eugenia. Ideias antirracistas brotavam tanto no campo da genética e da antropologia física quanto dos estudos sociológicos emergentes em diferentes lugares do mundo. No caso do Brasil, como já vimos, uma das críticas mais consistentes ao racismo científico vinha mesmo de Roquette-Pinto. Em livro publicado em 1933, o antropólogo fazia uma síntese de seus estudos sobre raça e populações e procurava justamente "provar" que os "males do Brasil" não eram de origem biológica ou racial, mas sim de ordem política, sanitária e educativa (Roquette-Pinto, 1933). Embora acreditasse que a eugenia pudesse contribuir para o aperfeiçoamento biológico humano, refutava medidas de seleção racial. $\mathrm{O}$ antropólogo inclusive utilizava a eugenia para demonstrar que os "cruzamentos raciais" não deveriam ser vistos como uma mistura de características heterogêneas, mas sim uma combinação de características genéticas e antropológicas (Roquette-Pinto, 1933, p. 171).

É importante destacar que o antirracismo de Roquette-Pinto não era um fato isolado no pensamento científico e intelectual do período. Desde o início do século XX, pensadores sociais, médicos e antropólogos começavam a negar os determinismos raciais como responsáveis pelos "males do Brasil". Autores como Manoel Bomfim e Alberto Torres, por exemplo, foram influências marcantes na percepção dos brasileiros sobre a centralidade da política, e não da questão racial, como o grande desafio do país. Mesmo no interior do movimento eugênico, outras vozes contrárias ao racismo científico se projetavam com legitimidade, entre eles o geneticista Octávio Domingues e os psiquiatras Juliano Moreira, Arthur Ramos e Antonio Austregésilo. Este último, por exemplo, chegou a apresentar em 1934, durante o Congresso Afro-brasileiro do Recife, o sugestivo trabalho "A mestiçagem no Brasil como fator eugênico", no qual fazia duras críticas ao racismo e ao "misticismo" que movia o arianismo alemão. Ao mesmo tempo que exaltava a "mestiçagem brasileira" como eugênica, apontava 
a fome, a doença, o analfabetismo e a "carência de cultura" como responsáveis por "nossa aparente inferioridade" (Austregésilo, 1937 [1934], p. 327).

Talvez o resultado mais paradigmático dessa tradição antirracista seja mesmo a publicação de Casa-grande \& Senzala, em 1933, livro seminal do sociólogo pernambucano Gilberto Freyre. A obra não apenas incorporava a crítica racial oriunda da tradição médica e antropológica brasileira como avançava na análise sociológica, ao defender a mestiçagem como um símbolo de distinção da identidade social e cultural do Brasil. Neste sentido, se o diálogo com a antropologia cultural de Franz Boas foi decisivo em sua maneira de considerar raça e cultura, também é verdade que Freyre aprendeu a valorizar a miscigenação com a antropologia de Roquette-Pinto, conforme confessara no prefácio à primeira edição de Casa-grande \& Senzala (Freyre, 2006, p. 31). Com ampla recepção no Brasil, as interpretações de Freyre exerceram forte impacto na construção de uma imagem positiva sobre o Brasil e a diversidade racial brasileira. A obra teve influência inclusive na maneira como o governo brasileiro projetou sua ambígua ideologia nacional: entre a exaltação do Brasil mestiço e racialmente democrático e a imposição de barreiras raciais à imigrantes indesejáveis.

Como expressão desse movimento antirracista, em 1935, Gilberto Freyre, Roquette-Pinto e Arthur Ramos lideraram um grupo de intelectuais que assinaram "O manifesto dos intelectuais brasileiros contra o preconceito racial". O documento chamava a atenção para a expansão do racismo e das ideologias que estimulavam rivalidades nacionais a partir de distinções raciais. De acordo com os signatários, numa clara referência ao radicalismo eugênico e às ideologias arianistas, "as correntes racistas surgidas ultimamente" devem ser vistas "como verdadeiras perversões de ideias científicas, desvirtuadas ainda pela sua associação arbitrária a fantasias e mitos pseudocientíficos” (Ramos, 1943 [1935], p. 172). Por fim, o documento conclamava os intelectuais a lutarem contra o racismo, destacando o risco que essas "doutrinas raciais" representavam para o Brasil, país "cuja formação étnica é acentuadamente heterogênea”. Em tais condições, afirmavam os signatários, "introduzir no Brasil as tendências dos racismos exóticos seria monstruosa inépcia, de que poderiam advir perigos imprevisíveis" (Ramos, 1943, p. 173).

\section{CONSIDERAÇÕES FINAIS}

É preciso dizer que o antirracismo brasileiro das primeiras décadas do século XX apresentava ambiguidades típicas de um período em que as frontei- 
ras entre natureza e cultura ainda não estavam estabelecidas. Mesmo a antropologia de Gilberto Freyre, conforme lembra Ricardo Benzaquen de Araújo (1994), era mediada pela biologia neolamarckista, o que permitia fundir raça, meio e cultura. Ao mesmo tempo, os intelectuais antirracistas também não eram imunes ao elitismo e ao autoritarismo brasileiros, nem às visões eurocêntricas sobre os sentidos do progresso biológico e da civilização humana, o que limitava a capacidade de compreenderem os paradoxos que distinguiam os grupos humanos. Não é por acaso que esse pensamento antirracista flertava frequentemente com as ambiguidades raciais, eugênicas e antropológicas. A própria adesão à eugenia pelos intelectuais antirracistas faz parte dessa ambivalência, uma vez que compartilhavam da crença generalizada sobre a possibilidade de melhoramento racial das futuras gerações.

Exemplo ainda mais emblemático dessa ambivalência é o peso que o paradigma do branqueamento exercia sobre as intepretações raciais. Neste caso, nem mesmo intelectuais como Roquette-Pinto deixavam de projetar, no futuro, uma nação racialmente mais homogênea e próxima das populações europeias, o que explicava a preferência pela entrada de imigrantes europeus. Além disso, embora negassem a existência de hierarquias raciais, era comum atribuírem as diferenças comportamentais às características fisiológicas, o que permitia interpretações valorativas sobre os distintos "temperamentos psicológicos". Outra ambiguidade bastante generalizada foi a criação de narrativas e interpretações mitológicas sobre as relações raciais e a existência de uma harmoniosa unidade nacional. Essas narrativas não apenas legitimavam o mito da democracia racial como suavizaram as explicações sobre a violência que o colonialismo, o racismo e a escravidão representaram na formação das desigualdades raciais, ignorando muitas vezes a existência do preconceito e da segregação racial.

Contudo, as visões antirracistas precisam ser consideradas dentro dos estreitos limites ideológicos, sociais e científicos existentes no início do século $\mathrm{XX}$, quando o nacionalismo, o racismo científico, o darwinismo social e o eurocentrismo foram ideologias estruturantes da maneira de pensar a formação das nações. Nesse período, embora os intelectuais antirracistas procurassem explicações próprias para pensar os problemas nacionais, continuaram, em boa medida, dependentes das teorias que os europeus produziam sobre a identidade racial brasileira. De acordo com Sérgio Carrara (2004, p. 431), devido à posição subalterna que o Brasil ocupava no cenário internacional, os intelectuais brasileiros "tinham que se opor a certas ideias e teorias produzidas pelas elites metropolitanas, das quais, entretanto, não podiam discordar, pois delas 
emanava em larga medida seu prestígio". Dependentes dessa posição "subalterna”, os eugenistas viviam entre o dilema de negarem as teorias científicas que indicavam a suposta decadência do Brasil, ao mesmo tempo que dependiam dessa ciência para apontar possíveis caminhos para a regeneração nacional.

Apesar das limitações e dos paradoxos do pensamento antirracista, é importante destacar que, a partir de meados dos anos 1930, as críticas ao radicalismo eugênico e racial ganhariam cada vez mais consistência. O próprio movimento eugênico se desarticularia institucionalmente com o fim da Comissão Central Brasileira de Eugenia e do Boletim de Eugenia, que teria seu último número publicado em 1933. Já no Estado Novo, apesar da manutenção de duras leis imigratórias, inclusive com relatos de perseguição a imigrantes judeus (Lesser, 1995; Geraldo, 2007), o racismo científico e a linguagem eugênica já não tinham mais a mesma recepção de outrora. Ao mesmo tempo, no final dos anos 1930 as críticas internacionais aos horrores da eugenia nazista também impactavam o mundo e colocavam o racismo e a eugenia na contramão da história. Nesse cenário, embora a eugenia e o racismo não tenham desaparecido, as interpretações mais recorrentes passaram a ser mesmo aquelas de intelectuais como Roquette-Pinto, Arthur Ramos e Gilberto Freyre, carregando consigo inclusive as ambivalências do seu tempo.

\section{REFERÊNCIAS}

ACTAS DO CONGRESSO DE EUGENIA. In: $1^{\circ}$ Congresso Brasileiro de Eugenia: Actas e Trabalhos. Rio de Janeiro. V. I. 1929. pp. 11-42.

ADAMS, Mark B. (Ed.). The Wellborn Science: Eugenics in Germany, France, Brazil, and Russia. New York: Oxford University Press, 1990.

AMARAL, Azevedo. O problema eugênico da imigração. In: $1^{\circ}$ Congresso Brasileiro de Eugenia: Actas e Trabalhos. Rio de Janeiro, 1929. pp. 327-340.

ARAÚJO, Ricardo Benzaquen de. Guerra e Paz: "Casa-grande \& Senzala" e a obra de Gilberto Freyre nos anos 30. Rio de Janeiro: Editora 34, 1994.

AUSTREGÉSILO, Antonio. A mestiçagem no Brasil como fator eugênico. In: FREYRE, Gilberto (Org.). Novos estudos afro-brasileiros, Rio de Janeiro: Civilização Brasileira, pp. 327-333, 1937 [1934].

CAROL, Anne. Histoire de l’eugénisme en France: les médecins et la procréation (XIXe-XXe siècle). Paris: Seuil, 1995.

CARRARA, Sérgio. Estratégias anticoloniais: sífilis, raça e identidade nacional no Brasil do entre-guerras. In: HOCHMAN, Gilberto; ARMUS, Diego (Orgs.). Cuidar, 
Controlar, Curar: ensaios históricos sobre saúde e doença na América Latina e Caribe. Rio de Janeiro: Fiocruz, 2004. pp. 428-453.

CARVALHO, Leonardo Dallacqua de. A eugenia no humor da revista ilustrada Careta: raça e cor no Governo Provisório (1930-1934). Dissertação (Mestrado em História) - Faculdade de Ciências e Letras de Assis, Universidade Estadual Paulista. Assis, 2014.

COUTO, Miguel. Discurso. In: Annaes da Assembleia Nacional Constituinte. Vol. 4, Imprensa Nacional: Rio de Janeiro, 1935. pp. 490-493.

DIWAN, Pietra. Raça pura: uma história da eugenia no Brasil e no mundo. São Paulo: Contexto, 2007.

FERREIRA, Jorge; DELGADO, Lucília de Almeida Neves (Orgs.). O Brasil Republicano: O tempo do nacional estatismo. Vol. 2: Do início da década de 1930 ao apogeu do Estado Novo. Rio de Janeiro: Civilização Brasileira, 2019.

FONSECA, Fróes da. Os grandes problemas da Antropologia. In: $1^{\circ}$ Congresso Brasileiro de Eugenia: Actas e Trabalhos. Rio de Janeiro, 1929. pp. 63-86.

FONSECA, Cristina M. Oliveira. Saúde no Governo Vargas (1930-1945): dualidade institucional de um bem público. Rio de Janeiro: Fiocruz, 2007.

FREYRE, Gilberto. Casa-grande \& Senzala: formação da família brasileira sob o regime de economia patriarcal. São Paulo: Global, 2006.

GERALDO, Endrica. O "perigo alienígena": política imigratória e pensamento racial no governo Vargas (1930-1945). Tese (Doutorado em História) - Instituto de Filosofia e Ciências Humanas, Universidade Estadual de Campinas. Campinas, 2007.

GUIMARÃES, Antonio Sérgio Alfredo. Racismo e antirracismo no Brasil. São Paulo: Editora 34, 2005.

KEHL, Renato. A eugenia no Brasil: esboço histórico e bibliográfico. In: $1^{\circ}$ Congresso Brasileiro de Eugenia: Actas e Trabalhos. Vol. 1. Rio de Janeiro, 1929a. pp. 45-62.

KEHL, Renato. Lições de eugenia. Rio de Janeiro: Livraria Francisco Alves, 1929b.

KEHL, Renato. Sexo e civilização - aparas eugênicas. Rio de Janeiro: Livraria Francisco Alves, 1933.

KEHL, Renato. Devem ser esterilizados os enfermos incuráveis? (Inquérito entre os cientistas brasileiros). O Globo, Rio de Janeiro, p. 1, 3 jan. 1934.

KEVLES, Daniel J. In the Name of Eugenics: Genetic and the Uses of Human Heredity. Nova York: Knopf, 1985.

HABIB, Paula Arantes Botelho Briglia. Agricultura e Biologia na Escola Superior de Agricultura Luiz de Queiroz (ESALQ): os estudos de genética nas trajetórias de Carlos Teixeira Mendes, Octavio Domingues e Salvador de Toledo Piza Jr. (19171937). Tese (Doutorado em História) - Fundação Oswaldo Cruz. Rio de Janeiro, 2010. 
HABIB, Paula Arantes Botelho Briglia. Eis o Mundo Encantado que Monteiro Lobato criou: raça, eugenia e nação. Dissertação (Mestrado em História) - Instituto de Filosofia e Ciências Humanas, Universidade de Campinas. Campinas 2003.

LESSER, Jeffrey. O Brasil e a questão judaica: imigração, diplomacia e preconceito. Rio de Janeiro: Imago, 1995.

LIMA, Nísia Trindade; HOCHMAN, Gilberto. Condenado pela raça, absolvido pela medicina: o Brasil descoberto pelo Movimento Sanitarista da Primeira República. In: MAIO, Marcos Chor; SANTOS, Ricardo Ventura. Raça, Ciência e Sociedade. Rio de Janeiro: Fiocruz, 1996. pp. 23-40.

MEIRA, Rubião. Fatores de degeneração de nossa raça: meios de combatê-los. In: Annaes de Eugenia. São Paulo: Revista do Brasil, 1919. pp. 49-64.

MOTA, André. Quem é bom já nasce feito: sanitarismo e eugenia no Brasil. Rio de Janeiro: DP\&A Editora, 2003.

MOURA, Olegário de. Saneamento-Eugenia-Civilização. In: Annaes de Eugenia. São Paulo: Revista do Brasil, 1919. pp. 80-92.

MUÑOZ, Pedro. Clínica, laboratório e eugenia: uma história transnacional das relações Brasil-Alemanha. Rio de Janeiro: Fiocruz; PUC-Rio, 2018.

O GLOBO. Devem ser esterilizados os enfermos incuráveis? O Globo. Rio de Janeiro, jan. 1934.

OLIVEIRA, Xavier de. Discurso. In: Annaes da Assembleia Nacional Constituinte. Vol. 6, Imprensa Nacional: Rio de Janeiro, 1935. pp. 449-482.

PROCTOR, Robert N. Racial Hygiene: Medicine Under the Nazis. Cambridge, MA; London: Harvard University Press, 1988.

RAMOS, Arthur. Manifesto dos intelectuais brasileiros contra o preconceito racial. In: RAMOS, Arthur (Org.). Guerra e relações de raça. Rio de Janeiro: UNE, 1943. pp. 171-174.

RAMOS, Jair de Souza. O ponto de mistura: raça, imigração e nação em um debate da década de 20. Dissertação (Mestrado em Antropologia) - Museu Nacional, Universidade Federal do Rio de Janeiro. Rio de Janeiro, 1994.

REBELO, Fernanda. A travessia: imigração, saúde e profilaxia internacional (18901926). Tese (Doutorado em História das Ciências e da Saúde) - Fundação Oswaldo Cruz, Programa de Pós-Graduação em História das Ciências e da Saúde. Rio de Janeiro, 2010.

REIS, José Roberto Franco. Higiene Mental e Eugenia: o projeto de "regeneração nacional" da Liga Brasileira de Higiene Mental (1920-30). Dissertação (Mestrado em História) - Instituto de Filosofia e Ciências Humanas, Universidade de Campinas. Campinas, 1994.

REPÚBLICA DOS ESTADOS UNIDOS DO BRASIL. Annaes da Assembleia Nacional Constituinte. 22 Vols. Imprensa Nacional: Rio de Janeiro, 1935. 
ROQUETTE-PINTO, Edgard. Notas sobre os tipos antropológicos do Brasil. In: $1^{\circ}$ Congresso Brasileiro de Eugenia: Actas e Trabalhos. Rio de Janeiro, 1929. pp. 119-147.

ROQUETTE-PINTO, Edgard. Ensaios de antropologia brasiliana. São Paulo: Cia Editora Nacional, 1933.

SANTOS, Ricardo Augusto dos. Lobato, os jecas e a questão racial no pensamento social brasileiro. Achegas, n. 7, 2003.

SCHWARTZMAN, Simon; BOMENY, Helena; COSTA, Vanda. Tempos de Capanema. Rio de Janeiro: Fundação Getúlio Vargas; Editora Paz e Terra, 2000.

SCHWARCZ, Lilia Moritz. O espetáculo das raças: cientistas, instituições e questão racial no Brasil. São Paulo: Companhia das Letras, 1993.

SEYFERTH, Giralda. Construindo a nação: hierarquias raciais e o papel do racismo na política de imigração e colonização. In: MAIO, Marcos Chor; SANTOS, Ricardo Ventura. Raça, Ciência e Sociedade. Rio de Janeiro: Fiocruz, 1996. pp. 41-58.

SKIDMORE, Thomas E. Preto no branco: raça e nacionalidade no pensamento brasileiro. São Paulo: Companhia das Letras, 2012.

SOUZA, Vanderlei Sebastião de. Em busca do Brasil: Edgard Roquette-Pinto e o retrato antropológico brasileiro (1905-1935). Rio de Janeiro: Fiocruz; FGV, 2017.

SOUZA, Vanderlei Sebastião de. Renato Kehl e a eugenia no Brasil: ciência, raça e nação no período entreguerras. Guarapuava: Editora Unicentro, 2019.

SPIRO, Jonathan Peter. Defending the Master Race: Conservation, Eugenics, and the Legacy of Madison Grant. New England: University Press of New England, 2009.

STEPAN, Nancy. A eugenia no Brasil - 1917-1940. In: HOCHMAN, Gilberto; ARMUS, Diego (Orgs.). Cuidar, Controlar, Curar: ensaios históricos sobre saúde e doença na América Latina e Caribe. Rio de Janeiro: Fiocruz, 2004. pp. 331-391.

STEPAN, Nancy. A Hora da Eugenia: raça, gênero e nação na América Latina. Rio de Janeiro: Fiocruz, 2005.

STERN, Alexandra Minna. Eugenic Nation: Faults and Frontiers of Better Breeding in Modern America. California: University of California Press, 2005.

TODOROV, Tzvetan. Nosotros y los otros: reflexión sobre la diversidad humana. México: Siglo XXI, 2005.

WEGNER, Robert; SOUZA, Vanderlei Sebastião de. Eugenia “negativa”, psiquiatria e catolicismo: embates em torno da esterilização eugênica no Brasil. História, Ciência, Saúde-Manguinhos, v. 20, n. 1, pp. 263-288, 2013.

WEGNER, Robert. Dois geneticistas e a miscigenação: Octavio Domingues e Salvador de Toledo Piza no movimento eugenista brasileiro (1929-1933). Varia Historia, v. 33, n. 61, pp. 79-107, 2017. 


\section{NOTAS}

${ }^{1}$ Essa associação entre neolamarckismo, sanitarismo e eugenia estava relacionada, no Brasil, à influência do pensamento médico francês, país que incorporou a eugenia à tradição higienista construída a partir dos séculos XVIII e XIX (Carol, 1995; Stepan, 2004). Assim como ocorreu na França, esse modelo de eugenia permitia pensar as reformas do meio, a educação sexual e a assistência materna-infantil como intervenções efetivas no processo de controle da hereditariedade humana e regeneração da população.

${ }^{2}$ Conforme a historiografia tem apontado, a eugenia foi empregada como símbolo de modernidade, transformando-se em linguagem corrente que aparecia não apenas nas discussões científicas sobre reprodução humana e hereditariedade, mas também em obras literárias de escritores como Monteiro Lobato, Jorge de Lima e Aldazira Bettencourt, entre outros, ou na obra de pensadores sociais e intérpretes do Brasil como Oliveira Vianna, Paulo Prado, Alfredo Ellis Junior e Azevedo Amaral. O mesmo podia ser notado no campo político, sobretudo da parte de autoridades públicas que atuavam para promover políticas de seleção racial e controle social (Habib, 2003; 2010; Santos, 2003; Stepan, 2004; Diwan, 2007; Souza, 2019).

Artigo submetido em 13 de abril de 2021. Aprovado em 30 de setembro de 2021. 